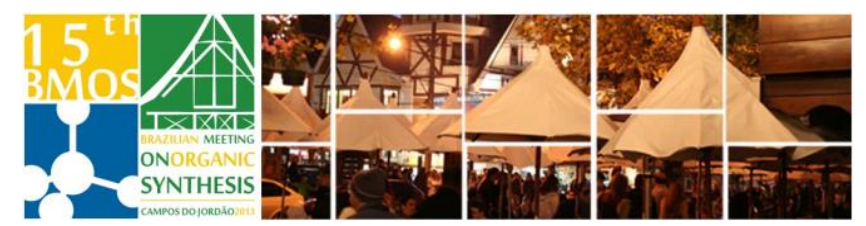

\title{
SYNTHESIS OF A NEW CHIRAL BIS-ARSINE LIGAND BASED ON NATURAL CARBOHYDRATES
}

\author{
Sol C. Parajón Puenzo ${ }^{\mathrm{a}, \mathrm{b}}$; Joaquín Arata Badano ${ }^{\mathrm{a}}$; Martin G. Lopez Vidal ${ }^{\mathrm{a}}$; Oscar \\ Varela $^{\text {; }}$; Sandra E. Martín ${ }^{a}$ \\ aINFIQC, Departamento de Química Orgánica, Facultad de Ciencias Químicas, Universidad Nacional de \\ Córdoba, Córdoba, Argentina - ${ }^{b}$ Dpto. Química Orgánica, CIHIDECAR-CONICET-UBA, Facultad de Ciencias \\ Exactas y Naturales, Buenos Aires, Argentina \\ *e-mail spuenzo@fcq.unc.edu.ar
}

Keywords: Chiral Ligand, Asymmetric Allylic Substitutions, Arsine

\section{INTRODUCTION}

Transition-metal-catalyzed asymmetric allylic substitutions have become one of the most powerful tools for asymmetric $\mathrm{C}-\mathrm{C}$ bond formation. ${ }^{1}$ Chiral diphosphine ligands have been some of the largest classes of ligands used in asymmetric substitutions. Trost developed the chiral ligand 1 (Fig. 1), which played a crucial role in the improvement of $\mathrm{Pd}$ catalyzed asymmetric substitutions. ${ }^{2}$ Based on the Trost modular ligand (TML) system 3 (Fig. 1) a family of ligands has been prepared. We recently reported the synthesis and application of the novel chiral bis-arsine ligand 2 derived from TML. ${ }^{3}$

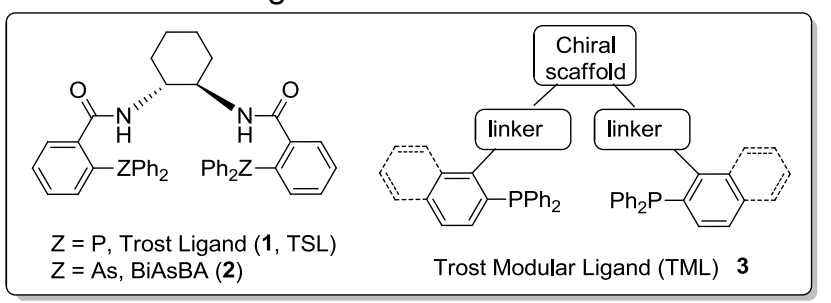

Figure 1. Phosphine and arsine Trost modular ligands.

Currently, significant attention has been turned towards the use of chiral ligands based on natural carbohydrates. ${ }^{4}$ Herein, we describe the synthesis of a chiral bis-arsine ligand such as 2 containing the chiral scaffold derived from a carbohydrate.

\section{RESULTS AND DISCUSSION}

The introduction of the diphenylarsine group was achieved by the Pd-catalyzed arsination of the ester 5, obtained after a Fischer sterification of carboxylic acid 4 (Fig. 2). Through hydrolysis of arsine ester the arsine containing carboxylic acid 6 was acquired. Treatment of D-glucosamine (7) with acetic anhydride provided the $\mathrm{N}$-acetyl glucosamine. After that the free anomeric hydroxyl group was protected with benzyl alcohol obtaining the sugar 8. A last protecting reaction was achieved with benzaldehyde in order to obtain the 4,6-O-benzylidene derivative. By desprotection of the amine group the carbohydrate 9 was achieved (Fig. 2). This key sugar intermediate was used as chiral scaffold to construct the arsine ligand. Finally, the condensation reaction of the free hydroxyl and amine groups of carbohydrate 9 with the arsine carboxylic acid 6 was performed, and the chiral bis-arsine ligand 10 was obtained.
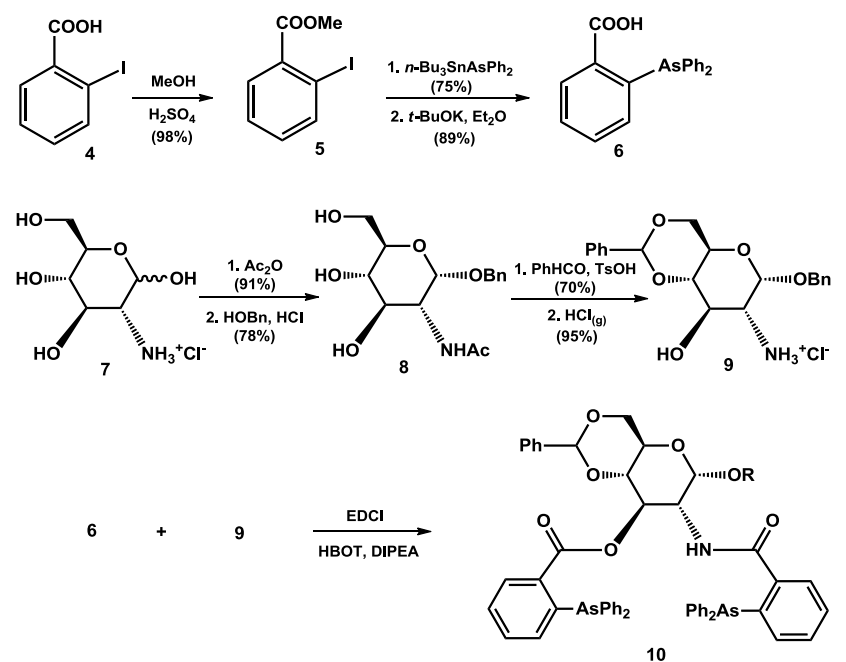

Figure 2. Synthesis of bis-arsine chiral igand

\section{CONCLUSION}

The sugar-based amino precursor 9 was synthesized straightforward from D-Glucosamine. This building block was employed as key intermediate in the synthesis of a new chiral bisarsine ligand.

\section{ACKNOWLEDGEMENTS}

We are grateful to ANPCyT, UBA, UNC and CONICET for their financial support.

\section{REFERENCES}

1. a) Trost, B. M.; Crawley, M. L. Chem. Rev. 2003, 103, 2921. b) Lu, Z.; Ma, S. Angew. Chem., Int. Ed. 2008, 120, 264.

2. Butts, C. P.; Filali, E.; Lloyd-Jones, G. C.; Norrby, P.-O.; Sale, D. A.; Schramm, Y.; J. Am. Chem. Soc. 2009, 131, 9945.

3. Uberman, P. M.; Caira M. R.; Martín, S. E., Organometallics 2013, 32, 3220.

4. a) Dieguez, M.; Claver, C.; Pamies, O. Eur. J. Org. Chem. 2007, 4621. b) Glegola, K.; Johannesen, S.; Thim, L.; Goux-Henry, C.; Skrydstrup, T.; Framey, E.; Tetrahedron Letters. 2008, 49, 6635. 